Discussion Paper No. 862

\title{
ENVIRONMENTAL REGULATION AND TECHNOLOGY TRANSFERS
}

\author{
Takao Asano \\ Noriaki Matsushima
}

December 2012

The Institute of Social and Economic Research Osaka University

6-1 Mihogaoka, Ibaraki, Osaka 567-0047, Japan 


\title{
Environmental regulation and technology transfers*
}

\author{
Takao Asano ${ }^{\dagger}$ \\ Faculty of Economics, Okayama University \\ Noriaki Matsushima ${ }^{\ddagger}$ \\ Institute of Social and Economic Research, Osaka University
}

This Version: December 13, 2012

\begin{abstract}
This paper analyzes the situation in which a national government introduces environmental regulations. Within the framework of an international duopoly with environmental regulations, this paper shows that an environmental tax imposed by the government in the home country can induce a foreign firm with advanced abatement technology to license it to a domestic firm without this technology. Furthermore, when the domestic firm's production technology is less efficient than that of the foreign firm, the foreign firm may freely reveal its technology to the domestic firm. These improvements through the voluntary transfer of technology support the Porter hypothesis, which states that environmental regulations have positive impacts on innovation.
\end{abstract}

JEL Classification Numbers: Q56, F18, H23, L13

Key Words: Environmental regulation; Technology transfer; International competition; Duopoly.

\footnotetext{
${ }^{*}$ We would like to thank Akihisa Shibata for his helpful comments. Financial support from Grant-in-Aid for Scientific Research (JSPS) is greatly acknowledged. Needless to say, we are responsible for any remaining errors.

$\dagger$ Takao Asano, Faculty of Economics, Okayama University, 3-1-1 Tsushimanaka, Kita-ku, Okayama 7008530, Japan. e-mail: asano@e.okayama-u.ac.jp. Phone: +81-86-251-7558.

¥ Correspondence author: Noriaki Matsushima, Institute of Social and Economic Research, Osaka University, 6-1 Mihogaoka, Ibaraki, Osaka 567-0047, Japan. Phone: +81-6-6879-8571. Fax: +81-6-6879-8583. E-mail: nmatsush@iser.osaka-u.ac.jp
} 


\section{Introduction}

This paper analyzes the situation in which a national government introduces environmental regulations. Based on an international duopoly model with environmental regulations, this paper shows that an environmental tax imposed by the government in the home country can induce a foreign firm with advanced abatement technology to license it to a domestic firm without this technology. Furthermore, when the domestic firm's production technology is less efficient than that of the foreign firm, the foreign firm may freely reveal its technology to the domestic firm.

Although the importance of environmental regulations has been recognized, many national governments, especially those in developing countries, seem hesitant to impose them because it is believed that these regulations can lower domestic firms' production (Ekins, 1999; European Commission, 2001). ${ }^{1}$ If such regulations were imposed, these firms would need support from foreign firms with advanced environmental technologies to overcome them. Thus, policymakers must understand whether the necessary advanced environmental technologies would be transferred from foreign firms to domestic firms. Because both abatement and production technologies play an important role in firms' activities, we also investigate whether foreign firms that license their advanced abatement technologies would also provide or license their production technologies.

This second question is important because technology transfers from developed countries to developing countries have received extensive attention (Horiuchi and Ishikawa, 2009). Substantial north-south technology spillovers have been well established empirically (Coe et al., 1997; Miller and Upadhyay, 2000), but these spillovers were involuntary. If foreign firms have incentives to voluntarily provide production technology to domestic firms, we can

\footnotetext{
${ }^{1}$ Contrary to this tendency, most European countries do have high levels of environmental taxation compared to the United States and some other countries (Sterner and Köhlin, 2003). In fact, as reported by the OECD (2012), the revenues from environmentally related taxes measured as a percent of GDP in 2009 were, for example, 3.99\% in Denmark, 3.50\% in Turkey, 2.85\% in Sweden, $1.32 \%$ in Argentina, $1.27 \%$ in China, and $0.81 \%$ in the United States. For a discussion of environmental taxation in the United Kingdom, see Dresner et al. (2006).
} 
conclude that these foreign firms would not have to fear involuntary production technology spillovers through north-south trade when they can license their environmental technologies to domestic firms.

To analyze these situations, we consider an international duopoly model with environmental regulations. ${ }^{2}$ We suppose that one domestic firm and one foreign firm exist and that the foreign firm is more efficient than the domestic one. The domestic firm does not have an abatement technology to reduce pollutants, whereas the foreign firm does have such a technology. To reduce pollutants, the government in the home country imposes an environmental tax if the foreign firm does not transfer its abatement technology.

Using a simple duopoly model, we show that the abatement technology can be transferred from the foreign firm to the domestic firm. Moreover, if the foreign firm has a chance to transfer its production technology before it determines whether to license its abatement technology, it may reveal its production information freely. It may seem like this production technology transfer would not benefit the foreign firm because it would improve the production efficiency of the rival domestic firm. However, this is not always true. When the domestic firm is very efficient, the government tends to set a higher environmental tax level to reduce the quantity supplied by the domestic firm. The foreign firm can therefore charge higher royalties for the abatement technology license because the domestic firm has a stronger incentive to escape the environmental tax. Anticipating this higher royalty fee, the foreign firm has an incentive to provide its production technology before it determines whether to license its abatement technology. This transfer is Pareto improving given that the foreign firm will license its abatement technology irrespective of the production technology transfer decision. This property of free-revelation can hold true even when we consider the case in which the licenser charges a lump-sum fee. ${ }^{3}$ Furthermore, we compare the two fee

\footnotetext{
${ }^{2}$ Burret and Sempere (2003), Lai and Hu (2008), and Baski and Chaudhuri (2009) investigate pollution problems in the context of international competition. They do not discuss firms' incentives to license abatement technologies, as discussed in this paper.

${ }^{3}$ Several works compare fees and royalties in oligopoly models (Wang, 1998; Sen, 2005).
} 
schedules and show that royalty licensing is more profitable for the licenser.

This result does not hold, however, when the government pre-commits itself to its environmental tax level. The production technology transfer is therefore more likely to occur if the government intends to adjust its environmental standard to fit the market environment. As mentioned earlier, many governments seem hesitant to impose environmental regulations, which reduces the possibility of a production technology transfer. A government's willingness to adjust its environmental standard also eliminates the foreign firms' fear of production technology spillovers because the effect of a production technology transfer is the same whether it is voluntary or involuntary.

Furthermore, our result is related to the Porter hypothesis. The Porter hypothesis (Porter and van der Linde, 1995) states that stringent environmental regulations could affect both innovation that improves the environment and firms' competitiveness. Many works empirically and theoretically discuss the validity of the Porter hypothesis by investigating the effects of environmental regulations on the growth rate of total factor productivity (Hamamoto, 2006), innovative activity (Hamamoto, 2006), global productivity (Bréchet and Jouvet, 2009), export competitiveness (Costantini and Mazzanti, 2011), the productivity of capital stock (Xepapadeas and de Zeeuw, 1999; Feichtinger et al., 2005), and endogenous technological change (Mohr, 2002). Our paper investigates the relationship between environmental regulations and technology transfers, which clearly have a positive impact on productivity. To the best of our knowledge, the effects of environmental regulations on technology transfers have not been analyzed. Therefore, our result complements the previous discussions on the Porter hypothesis.

Some researchers have already pointed out that firms with superior production or abatement technologies have incentives to license their technologies to their competitors (Rockett, 1990 and Regibeau and Gallegos, 2004). Rockett (1990) does not consider environmental technology transfers. Papers that do consider environmental technologies do not investigate production technology transfers, but, as in this paper, they do find that abatement technol- 
ogy transfers occur in oligopoly models where licensers directly compete with licensees in final product markets.

The possibility of technology transfers has been also investigated in the literature. Kabiraj and Marjit (2003) and Mukherjee and Pennings (2006) discuss the licensing incentives of firms with advanced production technologies. This paper is different from the other papers in several ways. First, this paper considers a licenser's incentive to transfer two types of technology, whereas previous papers only discuss production technology transfers. Second, unlike previous papers, we show that the free revelation of production technology can occur. Finally, these papers do not take into account pollution problems and instead focus on the possibility that tariffs induce a technology transfer from an advanced foreign firm to domestic firms. ${ }^{4}$

The organization of this paper is as follows. Section 2 provides our model. Section 3 analyzes two cases in which the host government imposes an environmental tax on the domestic and foreign firms. In the first case, the foreign firm does not license its abatement technology to the domestic firm, and in the second case, it does. In the latter case, both production and abatement technology can be transferred. Section 4 discusses the case in which the foreign firm uses a lump-sum fee when it licenses its abatement technology. Section 5 analyzes a different timing structure to check the robustness of the results in Section 3. Section 6 discusses further extensions. Section 7 concludes.

\section{The Model}

In this section, we provide our model. We consider a market with two firms $(f$ and $h)$ that produce a homogeneous product. Firm $f$ is in a foreign country, and firm $h$ is in the home country. Firm $f$ produces a unit of product at no marginal cost, and firm $h$ produces at a constant marginal cost $c \in(0,1 / 2)$, so that firm $h$ is less efficient than firm $f$. There

\footnotetext{
${ }^{4}$ Furusawa, Higashida, and Ishikawa (2004) and Ishikawa and Okubo (2009) investigate the effects of several governmental policies in international oligopoly models with externalities. Iida and Takeuchi (2009) investigate the effect of a tariff on the incentives of a foreign firm in an international duopoly model.
} 
are no fixed costs to production. We consider quantity competition.

Let $x_{i}$ be firm $i$ 's output level $(i=f, h)$. The inverse demand function for the homogeneous products is

$$
p=1-x_{f}-x_{h} .
$$

In the production process, firm $h$ generates pollutants that damage the environment of the home country. The environmental pollutants generated by firm $h$ with output level $x_{h}$ are

$$
E D \equiv \gamma x_{h}^{2},
$$

where $\gamma$ denotes the degree of environmental damage. For analytical simplicity, we assume that $\gamma>1 / 2$. In order to reduce pollutants that affect social welfare in the home country, the government in the home country imposes an environmental tax that maximizes the domestic surplus. Because firm $f$ has advanced abatement technology, firm $f$ does not emit any pollutants, which implies that the environmental tax is not imposed on firm $f$. The amount of tax paid by firm $h$ is $t x_{h}$, where $t$ is a constant value. In this paper, $t$ can be negative because of the government's incentive to protect the domestic firm, as in the context of strategic trade policy (Brander and Spencer, 1985). As shown in the next section, this assumption is not necessary to derive the main results, but it allows us to simplify the exposition. In this case, firm f's marginal cost of production is zero, and firm $h$ 's marginal cost of production is $c+t$.

Firm $h$ can escape the pollution tax if firm $f$ licenses its abatement technology, which eliminates pollutants. Firm $f$ licenses this technology at a royalty rate $r$. The total royalty firm $h$ must pay depends on the quantity of the product that it supplies. In this case, firm $f$ 's marginal cost of production is zero, and firm $h$ 's marginal cost of production is $c+r$.

\section{Royalty Licensing}

In this section, we consider an environmental tax both without and with licensing. In the first case, the game is a simple two-stage quantity-setting model; the regulator imposes the 
tax rate $t$, and each firm simultaneously determines its quantity supplied. In the second case, firm $f$ first decides whether to license its technology to firm $h$, the regulator then imposes the tax rate $t$ if licensing does not occur, and finally, each firm simultaneously determines its quantity supplied.

\subsection{No licensing versus licensing}

We first consider the case in which firm $f$ does not license its abatement technology. Suppose that the marginal costs of firms $f$ and $h$ are $c_{f}$ and $c_{h}$, respectively. Applying the standard calculation in Cournot competition to this problem, we have $x_{f}=\left(1+c_{h}-2 c_{f}\right) / 3$, $x_{h}=\left(1+c_{f}-2 c_{h}\right) / 3, \pi_{f}=x_{f}^{2}$, and $\pi_{h}=x_{h}^{2}$. Now, the marginal costs of firms $f$ and $h$ are 0 and $c+t$, respectively. The profits of the firms and the consumer surplus are

$$
\pi_{f}=x_{f}^{2}=\frac{(1+c+t)^{2}}{9}, \quad \pi_{h}=x_{h}^{2}=\frac{(1-2 c-2 t)^{2}}{9}, \quad C S=\frac{(2-c-t)^{2}}{18} .
$$

The domestic social surplus (the objective of the government) is

$$
\begin{aligned}
S W & =C S+\pi_{h}+t x_{h}-\gamma x_{h}^{2} \\
& =\frac{3\left(2-4 c+3 c^{2}\right)-2(1-2 c)^{2} \gamma-2(3(1-c)-4(1-2 c) \gamma) t-(3+8 \gamma) t^{2}}{18} .
\end{aligned}
$$

Solving the first-order condition, we find the optimal tax rate $t^{n}$ :

$$
t^{n}=-\frac{3(1-c)-4(1-2 c) \gamma}{3+8 \gamma} .
$$

The superscript " $n$ " denotes the case of no licensing. The profits of the firms are obtained as follows:

$$
\pi_{f}^{n}=\frac{4(c+2 \gamma)^{2}}{(3+8 \gamma)^{2}}, \quad \pi_{h}^{n}=\frac{(3-4 c)^{2}}{(3+8 \gamma)^{2}} .
$$

Next, we consider the case in which firm $f$ licenses its abatement technology to firm $h$ if possible. The marginal costs of firms $f$ and $h$ are 0 and $c+r$. Firm $f$ earns additional profits $\left(r x_{h}\right)$ from the licensing. The profits of the firms are

$$
\pi_{f}=\frac{(1+c+r)^{2}}{9}+r \frac{1-2 c-2 r}{3}, \quad \pi_{h}=\frac{(1-2 c-2 r)^{2}}{9} .
$$


When firm $f$ licenses its abatement technology, it faces the constraint that the ex post profit of firm $h$ must be larger than $\pi_{h}^{n}$ in (6). Otherwise, firm $h$ would reject the offer and pay the environmental tax. This condition is $(1-2 c-2 r)^{2} / 9>(3-4 c)^{2} /(3+8 \gamma)^{2}$, which implies that $r<t^{n}$. Under this constraint, firm $f$ licenses its technology if and only if $t^{n}>0 .{ }^{5}$ That is, if the environmental tax is positive and does not function as a subsidy to protect firm $h$ from firm $f$, firm $f$ has an incentive to license its abatement technology to firm $h$. The optimal royalty rate $r^{l}$ is equal to the optimal tax rate $t^{n}$, where the superscript "l" denotes licensing. This is because firm $f$ sets its royalty rate so that firm $h$ is indifferent between accepting and rejecting $f$ 's offer.

Proposition 1. If $t^{n}>0(\gamma>3(1-c) / 4(1-2 c)$ or $c<(4 \gamma-3) /(8 \gamma-3))$, firm $f$ licenses its technology to firm $h$. The royalty rate $r^{l}$ is equal to the optimal tax rate $t^{n}$, that is, $r^{l}=t^{n}$.

Then, the profits of the firms and the domestic surplus are given by:

$$
\begin{aligned}
& \pi_{f}^{l}=\frac{(3-4 c)(-3(1-c)+4(1-2 c) \gamma)+4(c+2 \gamma)^{2}}{(3+8 \gamma)^{2}}, \pi_{h}^{l}=\frac{(3-4 c)^{2}}{(3+8 \gamma)^{2}}, \\
& S W^{l}=\frac{27-60 c+36 c^{2}+8(3-2 c) \gamma+16 \gamma^{2}}{2(3+8 \gamma)^{2}} .
\end{aligned}
$$

\subsection{Free revelation of production technology}

We consider whether firm $f$ has an incentive to freely give its efficient production technology to firm $h$. We consider the following stage game. First, firm $f$ determines whether to provide its production technology to firm $h$. Second, firm $f$ decides whether to license its abatement technology to firm $h$. Third, the regulator imposes tax rate $t$ if the transfer of the abatement technology does not occur. Finally, each firm simultaneously determines its quantity supplied. That is, we add the first stage to the game discussed in the previous subsection. By comparing $\left.\pi_{f}^{l}\right|_{c=0}$ and $\pi_{f}^{l}$, we obtain the following proposition (the calculation is available in the Appendix).

\footnotetext{
${ }^{5}$ Firm $f$ licenses its abatement technology if its ex post profit is greater than $\pi_{f}^{n}$, that is, $(1+c+r)^{2} / 9+$ $r(1-2 c-2 r) / 3>(1+c+t)^{2} / 9$. Because the optimal royalty rate is equal to the optimal tax rate and $x_{h}=(1-2 c-2 r) / 3 \geq 0$, it follows that $f$ licenses its technology if and only if $t^{n}>0$.
} 
Proposition 2. Suppose that firm $f$ uses a royalty to license its abatement technology. When $c<\min \{(4 \gamma-3) /(8 \gamma-3), 3(8 \gamma-7) / 8(4 \gamma-1)\}$, the profits of the firms, the consumer surplus, and the social surplus are larger when firm $f$ freely reveals its production technology.

When $\gamma$ is large, as the marginal cost of firm $h$ decreases, the profits of firms $h$ and $f$ increase. In other words, firm $h$ 's efficiency improvements benefit firm $f$ when the degree of environmental damages generated by firm $h(\gamma)$ is large. When $c$ is small (firm $h$ is efficient), the quantity supplied by firm $h$ is large. Because more production leads to more pollution, firm $h$ must pay more taxes as it improves. This higher taxation level allows firm $f$ to set a higher royalty rate. This effect is represented by the difference between $r^{l}=t^{n}$ in (5) when firm $h$ 's marginal cost is zero and when it is $c:\left.r^{l}\right|_{c=0}-r^{l}=(8 \gamma-3) c /(8 \gamma+3)$. This difference is larger as the value of $\gamma$ increases. Therefore, when $\gamma$ is large $(\gamma>3(1-c) / 4(1-2 c)$ or $c<(4 \gamma-3) /(8 \gamma-3))$, a decrease in $c$ can be Pareto improving.

As shown in Proposition 2, if firm $f$ provides its production technology to firm $h$, then firm $h$ 's marginal cost changes from $c$ to zero, increasing the profits of both firms $h$ and $f$. Disclosing the efficient technology can therefore be Pareto improving. Our result implies that environmental regulation can improve production technology through a voluntary technology transfer and supports the well-known Porter hypothesis (Porter and van der Linde (1995)). Many works empirically and theoretically discuss the validity of the Porter hypothesis, and our result complements these previous discussions.

We implicitly assume that the government knows the efficiency levels of the firms (that is, the marginal costs of the firms) and the significance of the environmental damage caused by pollutants (that is, the value of $\gamma$ ). These implicit assumptions are not particularly restrictive. The first assumption is not restrictive if the government is able to observe the quantities supplied by the firms because these quantities reflect the efficiency levels of the firms. The more efficient a firm is, the more it produces. The second assumption is also not restrictive if governments are able to evaluate the effectiveness of firms' environmental 
technologies. In the automobile industry, governments set many grades of environmental standards because they are able to certify the emissions generated by products. Finally, the assumption of linear demand is not crucial to the results if the convexity of the environmental damage function, or in other words, $\gamma$, is large enough (this result is available in the Appendix (not for publication)).

\section{Lump-Sum Licensing}

We consider the case in which firm $f$ uses a lump-sum fee to license its abatement technology to firm $h$. To discuss the incentives of firm $f$, we compare the case where it does not license to the case where it does.

\subsection{Licensing}

The case in which firm $f$ does not license has already been discussed in section 3.1. The profits in this case are provided in (6).

Thus, we only consider the case in which firm $f$ licenses. The profits when firm $f$ licenses its abatement technology are given as $\pi_{f}=(1+c)^{2} / 9+F$ and $\pi_{h}=(1-2 c)^{2} / 9-F$, where $F$ is the lump-sum fee from firm $h$ to firm $f$. As in the case of royalties, we assume that firm $f$ (the licenser) has full bargaining power over firm $h$ (the licensee). Firm $h$ accepts the licensing contract if doing so does not lower its profit. Therefore, firm $f$ sets the maximum value of $F$ such that $\pi_{h} \geq \pi_{h}^{n}$, that is,

$$
F^{*}=\frac{4(3(1-c)-4(1-2 c) \gamma)(-3(2-3 c)-4(1-2 c) \gamma)}{9(3+8 \gamma)^{2}} .
$$

We derived the condition under which the environmental tax level is positive in Proposition 1 , which is equivalent to $c<(4 \gamma-3) /(8 \gamma-3)$. The value of $F$ in (9) is positive if $-3(2-$ $3 c)-4(1-2 c) \gamma<0$, that is, if $c<2(2 \gamma+3) /(8 \gamma+9)$. This inequality is satisfied if the environmental tax level is positive, that is, if $c<(4 \gamma-3) /(8 \gamma-3)$. Therefore, if $c<(4 \gamma-3) /(8 \gamma-3), F^{*}$ is positive. In other words, if the environmental tax level is 
positive, $F^{*}$ is also positive. The profits of the firms are

$$
\pi_{f}^{L}=\left(\frac{1+c}{3}\right)^{2}+F^{*}, \quad \pi_{h}^{L}=\left(\frac{1-2 c}{3}\right)^{2}-F^{*},
$$

where the superscript " $L$ " denotes licensing with a lump-sum payment.

We now check whether firm $f$ has an incentive to license its abatement technology, which is the case if the profit from licensing with a lump-sum fee is greater than that of no licensing (the calculation is available in the Appendix).

Proposition 3. If $c<\min \{(4 \gamma-3) /(8 \gamma-3),(21-4 \gamma) /(5(8 \gamma+9))\}$, firm $f$ has an incentive to license its abatement technology to firm $h$ through a lump-sum fee.

The first inequality, $c<(4 \gamma-3) /(8 \gamma-3)$, is the condition under which firm $h$ has an incentive to accept the licensing contract. This is similar to the case of a royalty. The second inequality, $c<(21-4 \gamma) /(5(8 \gamma+9))$, is the condition under which firm $f$ has an incentive to offer the licensing contract. In the case of a royalty, firm $f$ always has an incentive to offer its technology if firm $h$ has an incentive to accept the licensing contract. This result does not always hold when firm $f$ uses a lump-sum fee. When firm $f$ uses a royalty, the net marginal cost of firm $h$ is $c+r^{l}=c+t^{n}$ if firm $h$ accepts this offer. Firm $f$ keeps its cost advantage and earns the licensing revenue. When firm $f$ uses a lump-sum fee, however, the net marginal cost of firm $h$ is $c$, not $c+t^{n}$, if firm $h$ accepts this offer. Firm $f$ loses its cost advantage even though it earns the licensing revenue. ${ }^{6}$

When $c$ is large, this negative effect is significant. The licensing contract lowers the equilibrium market price because the marginal cost of firm $h$ decreases. A larger firm has more output over which it can apply a decrease in price. Because the production level of firm $f$ is large when $c$ is large (when firm $h$ is less efficient), a decrease in price has a more negative impact on firm $f$. Therefore, when $c$ is large, firm $f$ has weak incentives to license its abatement technology.

\footnotetext{
${ }^{6}$ The right-hand side of the inequality in Proposition 3 can be rewritten as $c<(21-4 \gamma) / 5(9+8 \gamma)$. When $c$ is large enough, this inequality does not hold.
} 


\subsection{Free revelation of production technology}

We now check the conditions under which firm $f$ has an incentive to give its advanced production technology to firm $h$. As shown in the Appendix, the following proposition gives the result.

Proposition 4. Suppose that firm $f$ uses a lump-sum fee to license its abatement technology. If $c<\min \{(4 \gamma-3) /(8 \gamma-3),(21-4 \gamma) /(5(9+8 \gamma))\}$ and $c<2\left(-99+48 \gamma+64 \gamma^{2}\right) /(-99+$ $\left.240 \gamma+320 \gamma^{2}\right)$, firm $f$ has an incentive to give its production technology to firm $h$.

Firm $f$ does not give its production technology when $c$ is large. When firm $f$ uses a lump-sum fee, the net marginal cost of firm $h$ is $c$ rather than $c+t^{n}$. The free revelation of production technology eliminates firm f's cost advantage. When the production technology is revealed, the revenue from licensing, $F^{*}$ in (9), increases, but when $c$ is large, the costs of increased competition outweigh the benefits from the licensing revenue.

\subsection{Lump-sum fee versus royalty}

We now compare the cases where firm $f$ charges a royalty and where it charges a lumpsum fee. Given that the environmental tax level $t^{n}$ in (5) is positive, $\pi_{f}^{l}$ in (8) is greater than $\pi_{f}^{L}$ in (10), which leads to the following proposition. ${ }^{7}$

Proposition 5. Firm $f$ prefers a royalty to a lump-sum fee.

A royalty contract keeps firm $h$ in a less competitive position because it needs to pay a positive $r$ to firm $f$, which increases its marginal cost. On the other hand, a lump-sum fee contract makes firm $h$ more competitive because the contract does not increase its marginal cost. This difference is the key to this proposition.

\section{Extensions}

\footnotetext{
${ }^{7}$ A simple calculation leads to $\pi_{f}^{l}-\pi_{f}^{L}=((4(1-2 c) \gamma-3(1-c))(3(2+3 c)+4(1+10 c) \gamma)) / 9(3+8 \gamma)^{2}>0$.
} 
In this section, to analyze whether commitment to the environmental tax affects our results, we change the timing structure of the game. First, the government sets the tax level. Second, observing the tax level, firm $f$ determines whether to license its abatement technology and sets royalty rate $r$ when it licenses. Finally, given the decisions of the government and firm $f$, each firm sets its quantity supplied.

First, we consider the subgame in which firm $f$ does not license its abatement technology. We only consider the case where $t \leq 0$ because firm $f$ has an incentive to license its technology if $t>0$. When $t \leq 0$, the outcome in this subgame is similar to that in the previous section. That is, $\pi_{f}, \pi_{h}$, and $C S$ are described in (3), and $S W$ is described in (4). Given the outcome, the optimal tax is $t^{n}$ in (5), and the welfare level is $S W^{c n}=\left(3-6 c+4 c^{2}+2 \gamma\right) / 2(3+8 \gamma)$, where the superscript " $c n$ " denotes the case of commitment with no licensing. $t^{n}$ in (5) is negative if and only if $c>(4 \gamma-3) /(8 \gamma-3)$.

Second, we consider the subgame in which firm $f$ licenses its abatement technology. If the government induces firm $f$ to license its technology, then the optimal tax level is $t=\varepsilon$, where $\varepsilon$ is a sufficiently small positive value. To simplify the analysis, we assume that $t$ is zero and firm $f$ licenses its technology with $r=t=0$. Substituting $r=0$ and $\gamma=0$ into $S W$ in (4), we have $S W^{c l}=\left(2-4 c+3 c^{2}\right) / 6$, where the superscript "cl" denotes the case of commitment with licensing. In this case, the profit of firm $f$ monotonically increases in $c$. As shown in the Appendix, the following proposition holds.

Proposition 6. When the government pre-commits itself to the environmental tax, firm $f$ does not have an incentive to give its superior production technology to firm $h$.

From the difference between $S W^{c n}$ and $S W^{c l}$, we find that the government sets $t=0$ if $\gamma>3(1-c)^{2} / 2(1-2 c)(5-6 c)$. The right-hand side is smaller than $3(1-c) / 4(1-2 c)$, which is the threshold at which the tax rate is negative when the government does not commit to the tax rate. That is, when the government is able to commit to the tax rate, firm $f$ tends to license its abatement technology. 
Commitment versus No commitment The domestic welfare ranking in the two games with different timing structures is ambiguous. The difference between $S W^{c l}$ and $\left.S W^{l}\right|_{c=0}$ (because of the production technology transfer) is

$$
S W^{c l}-\left.S W^{l}\right|_{c=0}=\frac{(4(1-2 c) \gamma-3(1+c))(21-9 c+5(5-6 c) \gamma)}{6(3+8 \gamma)^{2}} .
$$

This difference is negative if $(4 \gamma-3) /(8 \gamma+3)<c$. That is, when the inequality holds, pre-committing to the tax rate does not improve the domestic surplus because it has two conflicting effects. On the one hand, when the government sets its tax rate in advance, firm $f$ always licenses its abatement technology if the tax rate is positive. Anticipating firm $f$ 's reaction, the government sets the tax rate at a positive but sufficiently small level. Therefore, pre-commitment can reduce the royalty rate $r$, which increases domestic welfare. On the other hand, pre-commitment does not induce firm $f$ to transfer its technology as it would when the government cannot commit its tax rate. Because the tax rate is pre-determined, firm $f$ cannot raise the royalty rate $r$ through a production technology transfer, which lowers domestic welfare. Those two effects trade off. As the value of $\gamma$ increases, licensing the abatement technology becomes more important for domestic welfare. As the value of $c$ increases, the production technology transfer becomes more important for domestic welfare. When $\gamma$ is large enough, pre-committing to the tax rate is beneficial because licensing is relatively more important than the production technology transfer. When $c$ is large enough, pre-committing to the tax rate is not beneficial because the production technology transfer is relatively more important than licensing.

\section{Discussions}

In this section, we discuss further extensions. The details of the discussions are available in the Appendix (not for publication).

Cost and quality In the previous sections, we investigated the effects of licensing on firms' behaviors by incorporating production cost heterogeneity into the standard Cournot 
model. The main results still hold even when we incorporate a quality difference between the firms by the following formulation. The utility of the representative consumer is given by $U=x_{f}+(1-c) x_{h}-\left(x_{f}+x_{h}\right)^{2} / 2+m$, where $m$ is a numeraire good. The inverse demand functions are given by $p_{f}=1-x_{f}-x_{h}$ and $p_{h}=1-c-x_{f}-x_{h}$, where $c$ represents the quality disadvantage of firm $h$. Under this assumption, we have the same results as those in the main text. Therefore, we can apply our main results to the case where firm $f$ can give its high quality technology to firm $h$.

Package license In the previous sections, we separately analyzed firm $f$ 's decisions to transfer its abatement technology and its production technology to firm $h$. However, it could offer both technologies as a package. When we incorporate the possibility of offering a package license into the model, as in the case of Section 3.2, firm $f$ licenses its technology to firm $h$ except the case in which $c$ and $\gamma$ are small. However, the optimal royalty rate is greater than the optimal tax rate, which is a stark contrast to the result obtained in Proposition 1. On the other hand, the welfare level is equivalent to that under the abatement technology licensing case.

Tariff and subsidy We next analyze the case in which the government imposes an export tariff on firm $f$ as well as an environmental tax on firm $h$. For that purpose, we suppose that after the licensing contract is determined, the government imposes the tariff on firm $f$. Firm $f$ has an incentive to provide its production technology and its abatement technology to firm $h$ when $c$ is small. That is, the main result does not qualitatively change even when we take into account a tariff on firm $f$. We can also consider the case in which the government gives a subsidy to firm $h$ and imposes an environmental tax on firm $h$. We can derive a result which is qualitatively similar to Proposition 2 although the outcome in the case where firm $f$ licenses differs from that in the basic model. 
Global welfare We can obtain some implications about global welfare using the basic model when an environmental tax is set to maximize the global social surplus. When firm $f$ does not freely reveal its production technology, the global social surplus increases because the tax setter internalizes the profit of firm $f$. When firm $f$ does freely reveal its production technology, the tax level set by a global welfare maximizer is higher than that set by a domestic welfare maximizer. Because firm $f$ sets its licensing fees at the tax levels in the two cases, the licensing fee in the former case is higher than that in the latter one. The production technology transfers induce the production costs of the two firms to be zero in both cases, which implies that the global surplus in each case monotonically increases with the total quantity supplied by the firms. The difference between the licensing fees in the two cases leads to the welfare difference in the two cases. As a result, the global surplus in which the tax setter maximizes the global surplus is smaller than that in which it maximizes the local surplus.

\section{Conclusion}

Using a duopoly model with environmental regulations, this paper has analyzed whether governmental environmental regulations induce advanced abatement technology transfers from a foreign firm to a local firm. In this setting, if the local firm produces without advanced abatement technologies, then it has to pay an environmental tax for generating pollutants. This paper has shown that abatement technology transfer does occur, enabling the local firm to produce without generating pollution and to avoid paying the environmental tax. Furthermore, this paper has shown that the foreign firm may transfer production technology as well as abatement technology because the foreign firm can increase its royalties from providing the environmental technology when the local firm produces more efficiently. The result supports the well-known Porter hypothesis (Porter and van der Linde (1995)), and thus this paper complements previous discussions of the Porter hypothesis.

\section{Appendix}


Proof of Proposition 2. The difference between $\left.\pi_{f}^{l}\right|_{c=0}$ and $\pi_{f}^{l}$ is given by

$$
\left.\pi_{f}^{l}\right|_{c=0}-\pi_{f}^{l}=\frac{c(3(8 \gamma-7)-8(4 \gamma-1) c)}{(3+8 \gamma)^{2}}
$$

which is zero when $c=0$ or $c=3(8 \gamma-7) / 8(4 \gamma-1)$. Because $\pi_{f}^{l}$ is a convex function with respect to $c, \pi_{f}^{l}$ is smaller than $\left.\pi_{f}^{l}\right|_{c=0}$ if and only if $c<3(8 \gamma-7) / 8(4 \gamma-1)$. Under this inequality, $C S^{l}$ and $\pi_{h}^{l}$ decrease in $c$, and $S W^{l}$ is largest when $c=0$, which proves Proposition 2.

Proof of Proposition 3. $\pi_{f}^{L}$ in (10) can be rewritten as

$$
\pi_{f}^{L}=\frac{-63+96 \gamma+128 \gamma^{2}-2\left(-99+48 \gamma+64 \gamma^{2}\right) c+c^{2}\left(-99+240 \gamma+320 \gamma^{2}\right)}{9(3+8 \gamma)^{2}} .
$$

Firm $f$ has an incentive to license if and only if $\pi_{f}^{L}$ in (12) is larger than $\pi_{n}^{f}$ in (6), that is,

$$
\pi_{f}^{L} \geq \pi_{f}^{n} \Leftrightarrow \frac{(3(1-c)-4(1-2 c) \gamma)(-3(7-15 c)+4(1+10 c) \gamma)}{9(3+8 \gamma)^{2}} \geq 0 .
$$

This is positive if $-3(7-15 c)+4(1+10 c) \gamma<0$, that is, $c<(21-4 \gamma) / 5(8 \gamma+9)$, which proves Proposition 3.

Proof of Proposition 4. Using $\pi_{f}^{L}$ in (12), we derive the partial derivative of firm $f^{\prime}$ 's profit with respect to $c$ :

$$
\frac{\partial \pi_{f}^{L}}{\partial c}=\frac{2\left(99-99 c-48 \gamma+240 c \gamma-64 \gamma^{2}+320 c \gamma^{2}\right)}{9(3+8 \gamma)^{2}} .
$$

The second partial derivative is given by

$$
\frac{\partial^{2} \pi_{f}^{L}}{\partial c^{2}}=\frac{2\left(-99+240 \gamma+320 \gamma^{2}\right)}{9(3+8 \gamma)^{2}} .
$$

When $\gamma>3 / 4$, this profit function is convex with respect to $c$. The lower bound of $\gamma$, $3 / 4$, is derived using the condition under which the environmental tax level is positive, $\gamma>3(1-c) / 4(1-2 c)$ in $(5)$ for $c \in[0,1 / 2)$. The inequality $\gamma>3 / 4$ fully covers the case that we mainly discuss. From the first-order condition $\partial \pi_{f}^{L} / \partial c=0$, the following $c$ minimizes the profit of firm $f$ :

$$
c=\frac{-99+48 \gamma+64 \gamma^{2}}{-99+240 \gamma+320 \gamma^{2}}
$$


If firm $f$ gives its advanced production technology to firm $h$, the value of $c$ becomes zero. When $c=0$, the profit of firm $f$ is

$$
\left.\pi_{f}^{L}\right|_{c=0}=\frac{-63+96 \gamma+128 \gamma^{2}}{9(3+8 \gamma)^{2}} .
$$

We now derive the value of $c$ such that the profit of firm $f$ is equal to that when $c=0$ :

$$
\pi_{f}^{L}-\left.\pi_{f}^{L}\right|_{c=0}=0 \Leftrightarrow \frac{c\left(198-99 c-96 \gamma+240 c \gamma-128 \gamma^{2}+320 c \gamma^{2}\right)}{9(3+8 \gamma)^{2}}=0 .
$$

This equation is satisfied when $c=2\left(-99+48 \gamma+64 \gamma^{2}\right) /\left(-99+240 \gamma+320 \gamma^{2}\right)$. Because $\pi_{f}^{L}$ is a convex function with respect to $c, \pi_{f}^{L}$ is smaller than $\left.\pi_{f}^{L}\right|_{c=0}$ if and only if

$$
c<\frac{2\left(-99+48 \gamma+64 \gamma^{2}\right)}{-99+240 \gamma+320 \gamma^{2}}
$$

which proves Proposition 4.

Proof of Proposition 6. We now show that when the government pre-commits to the environmental tax rate, firm $f$ never gives its production technology to firm $h$.

When the government sets its tax rate at $t$, the maximum level of the licensing fee is $r=\min \{t, \bar{r}\}$, where $\bar{r}=\arg \max _{r} x_{f}^{2}+r x_{h}=(5-4 c) / 10$. When $r=t$, the profit of firm $f$ is $\pi_{f}=\left((1+c)^{2}+(5-4 c) t-5 t^{2}\right) / 9$. This is larger than $\left.\pi_{f}\right|_{c=0}$ for any $t<(1-2 c) / 2($ this inequality ensures that the quantities supplied by the firms are positive). When $r=\bar{r}$, the profit of firm $f$ is $\pi_{f}=\left(5+4 c^{2}\right) / 20$. This is larger than $\left.\pi_{f}\right|_{c=0}$. These results imply that firm $f$ is not willing to give its production technology to firm $h$.

\section{References}

[1] Ambec, S. and P. Barla (2002): "A Theoretical Foundation of the Porter Hypothesis," Economics Letters 75, 355-360.

[2] Baksi, S. and A. R. Chaudhuri (2009): "On Trade Liberalization and Transboundary Pollution," Economics Bulletin 29, 2605-2612. 
[3] Brander, J.A. and B.J. Spencer (1985): "Export subsidies and international market share rivalry," Journal of International Economics 18, 83-100.

[4] Bréchet, T. and P.-A. Jouvet (2009): "Why Environmental Management May Yield No-Regret Pollution Abatement Options," Ecological Economics 68, 1770-1777.

[5] Burguet, R. and J. Sempere (2003): "Trade Liberalization, Environmental Policy, and Welfare," Journal of Environmental Economics and Management 46, 25-37.

[6] Coe, D. T., E. Helpman, and A.W. Hoffmaister, (1997): "North-South R and D Spillovers," Economic Journal 107, 134-49.

[7] Costantini, V. and M. Mazzanti (2012): "On the Green and Innovative Side of Trade Competitiveness? The Impact of Environmental Policies and Innovation on EU Exports," Research Policy 41, 132-153.

[8] Dresner, S., T. Jackson, and N. Gilbert (2006): "History and Social Responses to Environmental Tax Reform in the United Kingdom," Energy Policy 34, 930-939.

[9] Ekins, P. (1999): "European Environmental Taxes and Charges: Recent Experoence, Issues, and Trends," Ecological Economics 31, 39-62.

[10] European Commission (2001): Study of the Economic and Environmental Implications of the Use of Environmental Taxes and Charges in the European Union and Its Member States.

[11] Feichtinger, G., R. F. Hartl, P. M. Kort, and V. M. Veliov (2005): "Environmental Policy, the Porter Hypothesis and the Composition of Capital: Effects of Learning and Technological Progress," Journal of Environmental Economics and Management 50, 434-446.

[12] Furusawa, T., K. Higashida, and J. Ishikawa (2004): "Tariffs versus Quotas in the Presence of Imperfect Competition and Cross-Border Externalities," Canadian Journal of Economics 37, 445-458.

[13] Hamamoto, M. (2006): "Environmental Regulation and the Productivity of Japanese Manufacturing Industries," Resource and Energy Economics 28, 299-312.

[14] Horiuchi, E. and J. Ishikawa (2009): "Tariffs and Technology Transfer through an Intermediate Product," Review of International Economics 17, 310-326.

[15] Iida, T. and K. Takeuchi (2009): "Environmental Technology Transfer via Free Trade," Economics Bulletin 30, 948-960. 
[16] Ishikawa, J. and T. Okubo (2010): "Environmental and Trade Policies for Oligopolistic Industry in the Presence of Consumption Externalities," International Economy 14, 59-76.

[17] Kabiraj, T. and S. Marjit (2003): "Protecting Consumers through Protection: The Role of Tariff-induced Technology Transfer," European Economic Review 47, 113-124.

[18] Lai, Y. and C. Hu (2008): "Trade Agreements, Domestic Environmental Regulation, and Transboundary Pollution," Resource and Energy Economics 30, 209-228.

[19] Miller, S. M. and M.P. Upadhyay, (2000): "The Effects of Openness, Trade Orientation, and Human Capital on Total Factor Productivity," Journal of Development Economics 63, 399-423.

[20] Mohr, R. D. (2002): "Technical Change, External Economies, and the Porter Hypothesis," Journal of Environmental Economics and Management 43, 158-168.

[21] Mukherjee, A. and E. Pennings (2006): "Tariffs, Licensing and Market Structure," European Economic Review 50, 1699-1707.

[22] OECD (2012): "The OECD/EEA database on instruments used for environmental policy and natural resources management," (May 5, 2012).

[23] Porter, M. E. and C. van der Linde (1995): "Toward a New Conception of the Environment-Competitiveness Relationship," Journal of Economic Perspectives 9, 97118.

[24] Regibeau, P. M. and A. Gallegos (2004): "Managed Trade, Trade Liberalisation and Local Pollution," Advance in Economic Analysis and Policy 4 (2) Article 5.

[25] Rockett, K. (1990): "The Quality of Licensed Technology," International Journal of Industrial Organization 8, 559-574.

[26] Sen, D. (2005). "Fee versus Royalty Re-Considered," Games and Economic Behavior $53,141-147$.

[27] Stern, T. and G. Köhlin (2003): "Environmental Tax in Europe," Public Finance and Management 3, 117-142.

[28] Wang, X. W. (1998): "Fee versus Royalty Licensing in a Cournot Duopoly Model," Economics Letters 60, 55-62.

[29] Xepapadeas, A. and A. de Zeeuw (1999): "Environmental Policy and Competitiveness: The Porter Hypothesis and the Composition of Capital," Journal of Environmental Economics and Management 37, 165-182. 


\section{Appendix (not for publication)}

\section{Packaging}

We consider the case in which firm $f$ licenses its abatement technology and its production technology as a package to firm $h$ if possible. From (1), the profit functions of firms $f$ and $h$ are

$$
\pi_{f}=\left(1-x_{f}-x_{h}\right) x_{f}+r x_{h}, \quad \pi_{h}=\left(1-x_{f}-x_{h}-r\right) x_{h} .
$$

The first-order conditions lead to

$$
x_{f}=\frac{1+r}{3}, \quad x_{h}=\frac{1-2 r}{3} .
$$

From (A.1) and (A.2), the profits of the firms and the consumer surplus are

$$
\pi_{f}=\frac{(1+r)^{2}}{9}+r \frac{1-2 r}{3}, \quad \pi_{h}=\frac{(1-2 r)^{2}}{9}, \quad C S=\frac{(2-r)^{2}}{18} .
$$

When firm $f$ licenses the package, it faces a constraint under which the ex post profit of firm $h$ must be larger than $\pi_{h}^{n}$ in (6). Otherwise, firm $h$ would reject the offer and pay the environmental tax. The condition is

$$
\frac{(1-2 r)^{2}}{9}>\frac{(3-4 c)^{2}}{(3+8 \gamma)^{2}} \rightarrow r<\frac{-3+6 c+4 \gamma}{3+8 \gamma} .
$$

Under this constraint, firm $f$ licenses its technology if and only if

$$
r>0 .
$$

Firm $f$ can choose $r$ to maximize $\pi_{f}$ in (A.3) under the above constraint on $r$. We easily find that this constraint is binding, thus, the optimal royalty rate $r^{p}$ is

$$
r^{p}=\frac{-3+6 c+4 \gamma}{3+8 \gamma}
$$

The superscript " $p$ " denotes package licensing. Contrary to the previous case, this optimal royalty rate is not equal to the optimal tax rate $t^{n}$ in (5). We summarize this result in the following proposition:

Proposition 7. If $c>(3-4 \gamma) / 6$, firm $f$ licenses its technology to firm $h$. The royalty rate is $r^{p}$ in (A.4). 
Licensing always occurs if abatement technology licensing occurs. Substituting (A.4) into (A.2) and (A.3), we have the equilibrium outcome in this case:

$$
\begin{aligned}
& x_{f}^{p}=\frac{2(c+2 \gamma)}{3+8 \gamma}, \quad x_{h}^{p}=\frac{3-4 c}{3+8 \gamma}, \quad C S^{p}=\frac{(3-2 c+4 \gamma)^{2}}{2(3+8 \gamma)^{2}}, \\
& \pi_{f}^{p}=\frac{(3-4 c)(-3+6 c+4 \gamma)+4(c+2 \gamma)^{2}}{(3+8 \gamma)^{2}}, \quad \pi_{h}^{p}=\frac{(3-4 c)^{2}}{(3+8 \gamma)^{2}}, \\
& S W^{p}=\frac{27-60 c+36 c^{2}+8(3-2 c) \gamma+16 \gamma^{2}}{2(3+8 \gamma)^{2}} .
\end{aligned}
$$

The welfare level is equivalent to that in the abatement technology licensing case.

\section{Tariff}

We consider the case in which the government imposes an export tariff on firm $f$ as well as an environmental tax on firm $h$. We assume that after the licensing contract is determined, the government imposes the tariff rate. That is, the government can revise the tariff rate after the competitive environment has changed.

No licensing First, we consider the case in which firm $f$ does not license its abatement technology. From (1), the profit functions of the firms (the objectives of the firms) are

$$
\pi_{f}=\left(1-x_{f}-x_{h}-\tau\right) x_{f}, \quad \pi_{h}=\left(1-x_{f}-x_{h}-c-t\right) x_{h},
$$

where $\tau$ is the tariff rate on firm $f$. The first-order conditions of the firms lead to

$$
x_{f}=\frac{1+c+t-2 \tau}{3}, \quad x_{h}=\frac{1-2 c-2 t+\tau}{3}, \quad p=\frac{1+c+t+\tau}{3} .
$$

From (A.8) and (A.9), the profits of the firms and the consumer surplus are

$$
\pi_{f}=\frac{(1+c+t-2 \tau)^{2}}{9}, \quad \pi_{h}=\frac{(1-2 c-2 t+\tau)^{2}}{9}, \quad C S=\frac{(2-c-t-\tau)^{2}}{18} .
$$

The domestic social surplus (the objective of the government) is

$$
S W=\frac{\left(x_{f}+x_{h}\right)^{2}}{2}+\pi_{h}+t x_{h}+\tau x_{f}-\gamma x_{h}^{2} .
$$

Solving the maximization problem of the government, we have the optimal tax rate $t^{T}$ and the optimal tariff rate $\tau^{T}$ :

$$
t^{T}=\frac{(2-3 c)(1-2 \gamma)}{2(1+3 \gamma)}, \quad \tau^{T}=\frac{c+2 \gamma}{2(1+3 \gamma)} .
$$


The superscript " $T$ " denotes the case in which the government imposes a tariff as well as an environmental tax. Substituting $t^{T}$ and $\tau^{T}$ in (A.12) into (A.9), (A.10), and (A.11), we have the equilibrium outcome in this case:

$$
\begin{aligned}
& x_{f}^{T}=\frac{c+2 \gamma}{2(1+3 \gamma)}, \quad x_{h}^{T}=\frac{2-3 c}{2(1+3 \gamma)}, \quad C S^{T}=\frac{(1-c+\gamma)^{2}}{2(1+3 \gamma)^{2}}, \\
& \pi_{f}^{T}=\frac{(c+2 \gamma)^{2}}{4(1+3 \gamma)^{2}}, \quad \pi_{h}^{T}=\frac{(2-3 c)^{2}}{4(1+3 \gamma)^{2}}, \quad S W^{T}=\frac{2-4 c+3 c^{2}+2 \gamma}{4(1+3 \gamma)} .
\end{aligned}
$$

Licensing Second, we consider the case in which firm $f$ licenses its abatement technology.

From (1), the profit functions of the firms are

$$
\pi_{f}=\left(1-x_{f}-x_{h}-\tau\right) x_{f}+r x_{h}, \quad \pi_{h}=\left(1-x_{f}-x_{h}-c-r\right) x_{h},
$$

where $\tau$ is the tariff rate. The first-order conditions of the firms lead to

$$
x_{f}=\frac{1+c+r-2 \tau}{3}, \quad x_{h}=\frac{1-2 c-2 r+\tau}{3}, \quad p=\frac{1+c+t+\tau}{3} .
$$

From (A.15) and (A.16), the profits of the firms and the consumer surplus are

$$
\pi_{f}=\frac{(1+c+r-2 \tau)^{2}}{9}, \quad \pi_{h}=\frac{(1-2 c-2 r+\tau)^{2}}{9}, C S=\frac{(2-c-r-\tau)^{2}}{18} .
$$

The domestic social surplus (the objective of the government) is

$$
S W=\frac{\left(x_{f}+x_{h}\right)^{2}}{2}+\pi_{h}+\tau x_{f} .
$$

Solving the maximization problem of the government, we have the optimal tariff rate $\tau^{T l}$ :

$$
\tau^{T l}=\frac{1}{3} .
$$

The superscript " $T l$ " denotes the case in which the government imposes a tariff after the licensing negotiation is achieved. Substituting $\tau^{T l}$ in (A.19) into (A.16), (A.17), and (A.18), we have the outcome given that the licensing term is $r$ :

$$
\begin{aligned}
& x_{f}=\frac{1+3 c+3 r}{9}, \quad x_{h}=\frac{2(2-3 c-3 r)}{9}, \quad C S=\frac{(5-3 c-3 r)^{2}}{81}, \\
& \pi_{f}=\frac{(1+3 c+3 r)^{2}}{81}+\frac{2 r(2-3 c-3 r)}{9}, \quad \pi_{h}=\frac{4(2-3 c-3 r)^{2}}{81}, \\
& S W=\frac{7-12 c+9 c^{2}-6(2-3 c) r+9 r^{2}}{18} .
\end{aligned}
$$

When firm $f$ licenses the abatement technology, it faces a constraint under which the ex post profit of firm $h$ must be greater than or equal to $\pi_{h}^{T}$ in (A.14). Otherwise, firm $h$ would 
reject the offer and pay the environmental tax. Firm $h$ accepts the licensing term $r$ if and only if

$$
\pi_{h} \text { in }(\mathrm{A} .20) \geq \pi_{h}^{T} \text { in }(\mathrm{A} .14) \Leftrightarrow \frac{4(2-3 c-3 r)^{2}}{81} \geq \frac{(2-3 c)^{2}}{4(1+3 \gamma)^{2}} .
$$

We can rewrite it as

$$
r \leq \frac{(2-3 c)(12 \gamma-5)}{12(1+3 \gamma)}
$$

When firm $f$ sets $r$ to maximize $\pi_{f}$ in (A.20) without considering the constraint, the optimal rate is

$$
r=\frac{7-6 c}{15} .
$$

If this $r$ is smaller than the value on the right-hand side of the inequality, this rate is optimal. Otherwise, the right-hand side value is the optimal rate. This is summarized in the following equation:

$$
r^{T l}= \begin{cases}\frac{(2-3 c)(12 \gamma-5)}{12(1+3 \gamma)} & \text { if } \gamma \leq 13 / 6 \text { or } c \geq 2(6 \gamma-13) /(3(12 \gamma-11)) \\ \frac{7-6 c}{15} & \text { if } \gamma \geq 13 / 6 \text { and } c \leq 2(6 \gamma-13) /(3(12 \gamma-11))\end{cases}
$$

Substituting it into (A.20), we have the outcome:

1. If $\gamma \leq 13 / 6$ or $c \geq 2(6 \gamma-13) /(3(12 \gamma-11))$,

$$
\begin{aligned}
& x_{f}^{T l}=\frac{-2+9 c+12 \gamma}{12(1+3 \gamma)}, \quad x_{h}^{T l}=\frac{2-3 c}{2(1+3 \gamma)}, \quad C S^{T l}=\frac{(10-9 c+12 \gamma)^{2}}{288(1+3 \gamma)^{2}}, \\
& \pi_{f}^{T l}=\frac{(-2+9 c+12 \gamma)^{2}}{144(1+3 \gamma)^{2}}+\frac{(2-3 c)^{2}(12 \gamma-5)}{24(1+3 \gamma)^{2}}, \quad \pi_{h}^{T l}=\frac{(2-3 c)^{2}}{4(1+3 \gamma)^{2}}, \\
& S W^{T l}=\frac{124-324 c+243 c^{2}+96 \gamma+144 \gamma^{2}}{96(1+3 \gamma)^{2}},
\end{aligned}
$$

2. If $\gamma \geq 13 / 6$ and $c \leq 2(6 \gamma-13) /(3(12 \gamma-11))$,

$$
\begin{aligned}
& x_{f}^{T l}=\frac{2(1-3 c)}{15}, \quad x_{h}^{T l}=\frac{4(1-3 c)}{15}, \quad C S^{T l}=\frac{(2-c)^{2}}{50}, \\
& \pi_{f}^{T l}=\frac{(4+3 c)^{2}}{225}+\frac{2(1-3 c)(7-6 c)}{225}, \quad \pi_{h}^{T l}=\frac{4(1-3 c)^{2}}{225}, \\
& S W^{T l}=\frac{28-18 c+27 c^{2}}{150} .
\end{aligned}
$$

We now check the conditions in which firm $f$ has an incentive to give its advanced production technology to firm $h$ before the licensing contract is achieved. If firm $f$ gives its 
advanced production technology to firm $h$, the value of $c$ becomes zero. When $c=0$, the profit of firm $f$ is

$$
\left.\pi_{f}^{T l}\right|_{c=0}= \begin{cases}\frac{-29+60 \gamma+36 \gamma^{2}}{36(1+3 \gamma)^{2}} & \text { If } \gamma \leq 13 / 6, \\ \frac{2}{15} & \text { If } \gamma \geq 13 / 6 .\end{cases}
$$

We now derive the value of $c$ such that the profit of firm $f$ is equal to that when $c=0$ :

$$
\left.\pi_{f}^{T l}\right|_{c=0}-\pi_{f}^{T l}=\left\{\begin{array}{cc}
\frac{3 c(24(1-c)-(12-7 c))}{16(1+3 \gamma)^{2}}, & \text { if } \gamma \leq 13 / 6, \\
\frac{676-1620 c+945 c^{2}-24\left(26-135 c+135 c^{2}\right) \gamma+144 \gamma^{2}}{720(1+3 \gamma)^{2}}>0 & \text { if } \gamma \geq 13 / 6 \text { and } c \geq 2(6 \gamma-13) /(3(12 \gamma-11)), \\
\frac{c(2-3 c)}{15}>0 & \text { if } \gamma \geq 13 / 6 \text { and } c \leq 2(6 \gamma-13) /(3(12 \gamma-11)) .
\end{array}\right.
$$

From this equation, $\left.\pi_{f}^{T l}\right|_{c=0}-\pi_{f}^{T l}>0$ if and only if

$$
c<\frac{12(2 \gamma-1)}{24 \gamma-7}
$$

Because $\pi_{f}^{T l}$ is a convex function with respect to $c$, we have the following proposition.

Proposition 8. If $c<12(2 \gamma-1) /(24 \gamma-7)$, firm $f$ has an incentive to give its production technology to firm $h$. The profit of firm $f, \pi_{f}^{T l}$, is given by (A.24).

\section{Subsidy}

We consider the case in which the government gives a subsidy to firm $h$ and imposes an environmental tax on firm $h$. We assume that after the licensing contract is determined, the government sets the subsidy rate. That is, the government can revise the subsidy rate after the competitive environment has changed.

No licensing First, we consider the case in which firm $f$ does not license its abatement technology. From (1), the profit functions of the firms (the objectives of the firms) are

$$
\pi_{f}=\left(1-x_{f}-x_{h}+s-t\right) x_{f}, \quad \pi_{h}=\left(1-x_{f}-x_{h}-c\right) x_{h},
$$

where $s$ is the subsidy rate on firm $h$. The first-order conditions of the firms lead to

$$
x_{f}=\frac{1+c+t-s}{3}, \quad x_{h}=\frac{1-2 c-2 t+2 s}{3}, \quad p=\frac{1+c+t-s}{3} .
$$


From (A.25) and (A.26), the profits of the firms and the consumer surplus are

$$
\pi_{f}=\frac{(1+c+t-s)^{2}}{9}, \quad \pi_{h}=\frac{(1-2 c-2 t+2 s)^{2}}{9}, \quad C S=\frac{(2-c-t+s)^{2}}{18} .
$$

The domestic social surplus (the objective of the government) is

$$
S W=\frac{\left(x_{f}+x_{h}\right)^{2}}{2}+\pi_{h}+t x_{h}-s x_{h}-\gamma x_{h}^{2} .
$$

In this case, a negative subsidy and a positive environmental tax have the same effect on the domestic social surplus. Both equivalently reduce the quantity supplied by firm $h$. Solving the maximization problem of the government, we have the optimal tax rate $t^{S}$ and the optimal subsidy rate $s^{S}$ :

$$
t^{S}-s^{S}=-\frac{3(1-c)-4(1-2 c) \gamma}{3+8 \gamma} .
$$

The superscript " $S$ " denotes the case in which the government imposes a subsidy as well as an environmental tax. This is equivalent to the tax level in (5). Therefore, the profits of the firms are those in (6):

$$
\pi_{f}^{S}=\frac{4(c+2 \gamma)^{2}}{(3+8 \gamma)^{2}}, \quad \pi_{h}^{S}=\frac{(3-4 c)^{2}}{(3+8 \gamma)^{2}}
$$

Licensing Second, we consider the case in which firm $f$ licenses its abatement technology.

The profit functions of the firms are

$$
\pi_{f}=\left(1-x_{f}-x_{h}\right) x_{f}+r x_{h}, \quad \pi_{h}=\left(1-x_{f}-x_{h}-c-r+s\right) x_{h},
$$

where $s$ is the tariff rate. The first-order conditions of the firms lead to

$$
x_{f}=\frac{1+c+r-s}{3}, \quad x_{h}=\frac{1-2 c-2 r+2 s}{3}, \quad p=\frac{1+c+t-s}{3} .
$$

From (A.31) and (A.32), the profits of the firms and the consumer surplus are

$$
\pi_{f}=\frac{(1+c+r-s)^{2}}{9}, \quad \pi_{h}=\frac{(1-2 c-2 r+2 s)^{2}}{9}, \quad C S=\frac{(2-c-r+s)^{2}}{18} .
$$

The domestic social surplus (the objective of the government) is

$$
S W=\frac{\left(x_{f}+x_{h}\right)^{2}}{2}+\pi_{h}-s x_{f} .
$$

Solving the maximization problem of the government, we have the optimal subsidy rate $\tau^{S l}$ :

$$
s^{S l}=1-c-r .
$$


The superscript "Sl" denotes the case in which the government imposes a subsidy after the licensing negotiation is achieved. Substituting $s^{S l}$ in (A.35) into (A.32), (A.33), and (A.34), we have the outcome given that the licensing term is $r$ :

$$
\begin{aligned}
& x_{f}=\frac{2(c+r)}{3}, \quad x_{h}=\frac{3-4 c-4 r}{3}, \quad C S=\frac{(3-2 c-2 r)^{2}}{18}, \\
& \pi_{f}=\frac{4(c+r)^{2}}{9}+\frac{r(3-4 c-4 r)}{3}, \quad \pi_{h}=\frac{(3-4 c-4 r)^{2}}{9} .
\end{aligned}
$$

When firm $f$ licenses the abatement technology, it faces a constraint under which the ex post profit of firm $h$ must be greater than or equal to $\pi_{h}^{S}$ in (A.30). Otherwise, firm $h$ would reject the offer and pay the environmental tax. Firm $h$ accepts the licensing term $r$ if and only if

We can rewrite it as

$$
\pi_{h} \text { in }(\mathrm{A} .36) \geq \pi_{h}^{S} \text { in }(\mathrm{A} .30) \Leftrightarrow \frac{(3-4 c-4 r)^{2}}{9} \geq \frac{(3-4 c)^{2}}{(3+8 \gamma)^{2}} .
$$

$$
r \leq \frac{2(3-4 c) \gamma}{3+8 \gamma}
$$

When firm $f$ sets $r$ to maximize $\pi_{f}$ in (A.36) without considering the constraint, the optimal rate is

$$
r=\frac{9-4 c}{16}
$$

If this $r$ is smaller than the value on the right-hand side of the inequality, this is the optimal rate. Otherwise, the right-hand side value is optimal. This is summarized in the following equation:

$$
r^{S l}= \begin{cases}\frac{2(3-4 c) \gamma}{3+8 \gamma} & \text { if } c \geq 1 / 4 \text { or } \gamma \leq(9-4 c) /(8(1-4 c)) \\ \frac{9-4 c}{16} & \text { if } c<1 / 4 \text { and } \gamma \geq(9-4 c) /(8(1-4 c)) .\end{cases}
$$

Substituting it into (A.36), we have the profit of firm $f$ :

$$
\pi_{f}^{S l}= \begin{cases}\frac{2(1+8 \gamma) c^{2}-16 \gamma c+\gamma(9+8 \gamma)}{(3+8 \gamma)^{2}} & \text { if } c \geq 1 / 4 \text { or } \gamma \leq(9-4 c) /(8(1-4 c)), \\ \frac{9-8 c+16 c^{2}}{32} & \text { if } c<1 / 4 \text { and } \gamma \geq(9-4 c) /(8(1-4 c)) .\end{cases}
$$

We now check the conditions in which firm $f$ has an incentive to give its advanced production technology to firm $h$ before the licensing contract is achieved. If firm $f$ gives its advanced production technology to firm $h$, the value of $c$ becomes zero. When $c=0$, the profit of firm $f$ is

$$
\left.\pi_{f}^{S l}\right|_{c=0}= \begin{cases}\frac{\gamma(9+8 \gamma)}{(3+8 \gamma)^{2}} & \text { if } c \geq 1 / 4 \text { or } \gamma \leq(9-4 c) /(8(1-4 c)) \\ \frac{9}{32} & \text { if } c<1 / 4 \text { and } \gamma \geq(9-4 c) /(8(1-4 c)) .\end{cases}
$$


We now derive the value of $c$ such that the profit of firm $f$ is equal to that in which $c=0$ :

$$
\left.\pi_{f}^{S l}\right|_{c=0}-\pi_{f}^{S l}= \begin{cases}\frac{2 c(8 \gamma-(1+8 \gamma) c)}{(3+8 \gamma)^{2}}, & \text { if } c \geq 1 / 4 \text { or } \gamma \leq(9-4 c) /(8(1-4 c)), \\ \frac{8 c(1-2 c)}{32}>0, & \text { if } c<1 / 4 \text { and } \gamma \geq(9-4 c) /(8(1-4 c)) .\end{cases}
$$

From this equation, $\left.\pi_{f}^{S l}\right|_{c=0}-\pi_{f}^{S l}>0$ if and only if

$$
c<\frac{8 \gamma}{8 \gamma+1}
$$

Because $\pi_{f}^{S l}$ is a convex function with respect to $c$, we have the following proposition.

Proposition 9. If $c<8 \gamma /(8 \gamma+1)$, firm $f$ has an incentive to give its production technology to firm $h$. The profit of firm $f, \pi_{f}^{S l}$, is given by (A.39).

\section{Global welfare}

We can obtain some implications about global welfare using the basic model when an environmental tax is set to maximize the global social surplus. The objective function includes the profit of firm $f$ as well as the domestic surplus in country $h$, which is a departure from the basic model.

When firm $f$ does not license, the environmental tax is set at

$$
t=\frac{-1+5 c+4(1-2 c) \gamma}{1+8 \gamma}
$$

The result is

$$
\begin{aligned}
& \pi_{f}=\frac{4(c+2 \gamma)^{2}}{(1+8 \gamma)^{2}}, \quad \pi_{h}=\frac{(1-4 c)^{2}}{(1+8 \gamma)^{2}}, \quad G W=\frac{1-2 c+4 c^{2}+6 \gamma}{2(1+8 \gamma)}, \\
& S W=\frac{1-2 c-4 c^{2}+2\left(7-24 c+16 c^{2}\right) \gamma+16 \gamma^{2}}{2(1+8 \gamma)^{2}} .
\end{aligned}
$$

The global social surplus increases when the objective of the tax setter changes in the case where firm $f$ never licenses its abatement technology.

When firm $f$ does license its abatement technology, the licensing fee is set at the tax level set when firm $f$ does not license, that is,

$$
r=t=\frac{-1+5 c+4(1-2 c) \gamma}{1+8 \gamma} .
$$


The result is

$$
\begin{aligned}
& \pi_{f}=\frac{4(c+2 \gamma)^{2}}{(1+8 \gamma)^{2}}+\frac{(-1+5 c+4(1-2 c) \gamma)(1-4 c)}{(1+8 \gamma)^{2}}, \pi_{h}=\frac{(1-4 c)^{2}}{(1+8 \gamma)^{2}}, \\
& G W=\frac{\left(1-2 c+4 c^{2}\right)(1+16 \gamma)+48 \gamma^{2}}{2(1+8 \gamma)^{2}}, \\
& S W=\frac{3-20 c+36 c^{2}+8(1-2 c) \gamma+16 \gamma^{2}}{2(1+8 \gamma)^{2}} .
\end{aligned}
$$

We find the change in the domestic and global surplus following licensing as follows:

$$
\Delta S W=\frac{(1-4 c)(1-5 c-(3-4 c) \gamma)}{(1+8 \gamma)^{2}}, \Delta G W=\frac{(1-4 c)^{2} \gamma}{(1+8 \gamma)^{2}} .
$$

Licensing can lower the domestic surplus when the tax setter maximizes the global social surplus.

Finally, we compare the case where the tax setter maximizes the local surplus to the case where it maximizes the global surplus. When $\gamma$ is large, firm $f$ not only licenses its abatement technology but also gives its production technology to firm $h$. When it does so in these two cases, the difference between the global surpluses is

$$
\Delta G W=\frac{1+16 \gamma+48 \gamma^{2}}{2(1+8 \gamma)^{2}}-\frac{9+48 \gamma+48 \gamma^{2}}{2(3+8 \gamma)^{2}}=\frac{64 \gamma^{2}(1+4 \gamma)}{(1+8 \gamma)^{2}(3+8 \gamma)^{2}}>0 .
$$

That is, the global surplus in which the tax setter maximizes the global surplus issmaller than that in which it maximizes the local surplus.

\section{General demand function}

We check how the functional form of the inverse demand affects the main result. We assume that $p(Q)$ is the inverse demand. As often assumed, $p^{\prime}<0$ and $p^{\prime \prime} \leq 0$.

The profit functions of the firms are given by

$$
\pi_{h}=(p(Q)-c-t) q_{h}, \quad \pi_{f}=p(Q) q_{f} .
$$

The first-order conditions of the firms are given by

$$
\begin{aligned}
\frac{\partial \pi_{h}}{\partial q_{h}} & =p^{\prime}(Q) q_{h}+p(Q)-c-t=0, \\
\frac{\partial \pi_{f}}{\partial q_{f}} & =p^{\prime}(Q) q_{f}+p(Q)=0, \\
\frac{\partial \pi_{h}}{\partial q_{h}}+\frac{\partial \pi_{f}}{\partial q_{f}} & =p^{\prime}(Q) Q+p(Q)-c-t=0 .
\end{aligned}
$$


The total differentials of the first and the third equations are given by

$$
\begin{aligned}
& p^{\prime \prime}(Q) q_{h} d Q+p^{\prime}(Q) d q_{h}+p^{\prime}(Q) d Q-d t=0, \\
& \left(p^{\prime \prime}(Q) Q+2 p^{\prime}(Q)\right) d Q-d t=0
\end{aligned}
$$

Arranging the equations, we have

$$
\begin{aligned}
& \left(p^{\prime \prime}(Q) q_{h}+p^{\prime}(Q)\right) \frac{d Q}{d t}+p^{\prime}(Q) \frac{d q_{h}}{d t}=1, \quad \frac{d Q}{d t}=\frac{1}{p^{\prime \prime}(Q) Q+2 p^{\prime}(Q)} \\
\rightarrow & \frac{d q_{h}}{d t}=\frac{p^{\prime \prime}(Q) q_{f}+p^{\prime}(Q)}{p^{\prime}(Q)\left(p^{\prime \prime}(Q) Q+2 p^{\prime}(Q)\right)}
\end{aligned}
$$

The social surplus in the home country is given by

$$
W=\int_{0}^{Q^{*}} p(m) d m-p\left(Q^{*}\right) Q^{*}+\left(p\left(Q^{*}\right)-c-t\right) q_{h}^{*}-E\left(q_{h}^{*}\right)+t q_{h}^{*},
$$

where $E(\cdot)$ is the economic cost of environmental damages. We assume that $E^{\prime}>0$ and $E^{\prime \prime}>0$. The first-order condition with respect to $t$ is given by

$$
\begin{aligned}
\frac{\partial W}{\partial t} & =-p^{\prime}\left(Q^{*}\right) Q^{*} \frac{d Q^{*}}{d t}+\left(t-E^{\prime}\left(q_{h}^{*}\right)\right) \frac{d q_{h}^{*}}{d t} \\
& =-p^{\prime}\left(Q^{*}\right) Q^{*} \times \frac{1}{p^{\prime \prime}\left(Q^{*}\right) Q^{*}+2 p^{\prime}\left(Q^{*}\right)}+\left(t-E^{\prime}\left(q_{h}^{*}\right)\right) \frac{p^{\prime \prime}\left(Q^{*}\right) q_{f}^{*}+p^{\prime}\left(Q^{*}\right)}{p^{\prime}\left(Q^{*}\right)\left(p^{\prime \prime}\left(Q^{*}\right) Q^{*}+2 p^{\prime}\left(Q^{*}\right)\right)}, \\
& =-\frac{1}{p^{\prime \prime}\left(Q^{*}\right) Q^{*}+2 p^{\prime}\left(Q^{*}\right)}\left(\left(p^{\prime}\left(Q^{*}\right)\right)^{2} Q^{*}-\left(t-E^{\prime}\left(q_{h}^{*}\right)\right)\left(p^{\prime \prime}\left(Q^{*}\right) q_{f}^{*}+p^{\prime}\left(Q^{*}\right)\right)\right)=0 .
\end{aligned}
$$

The equilibrium tax level is determined by the above equation. We define $G \equiv(t-$ $\left.E^{\prime}\left(q_{h}^{*}\right)\right)\left(p^{\prime \prime}\left(Q^{*}\right) q_{f}^{*}+p^{\prime}\left(Q^{*}\right)\right)$. The following figure captures how the tax level is determined.

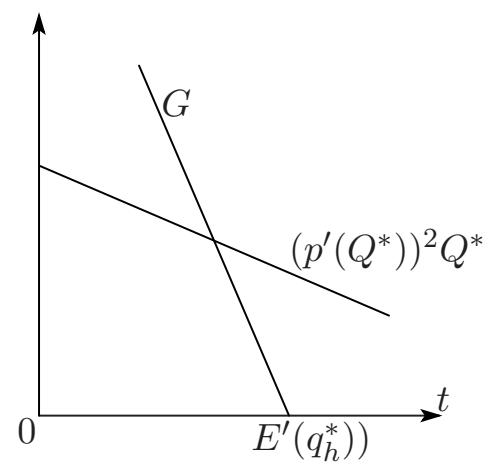

Using the first-order conditions of the firms, we have the following inequalities: $d Q^{*} / d c<0$, 
$d q_{h}^{*} / d c<0, d q_{f}^{*} / d c>0$. We now check how $\partial W / \partial t$ changes with a decrease in $c$.

$$
\begin{aligned}
\frac{d\left(\left(p^{\prime}\right)^{2} Q^{*}\right)}{d c}= & \underbrace{p^{\prime}}_{(-)} \underbrace{\left(2 p^{\prime \prime} Q^{*}+p^{\prime}\right)}_{(-)} \underbrace{\frac{d Q^{*}}{d c}<0,}_{(-)} \\
\frac{d G}{d c}= & \underbrace{-E^{\prime \prime}\left(q_{h}^{*}\right)}_{(-)} \underbrace{\left(p^{\prime \prime}\left(Q^{*}\right) q_{f}^{*}+p^{\prime}\left(Q^{*}\right)\right)}_{(-)} \underbrace{\frac{d q_{h}^{*}}{d c}}_{(-)} \\
& +\underbrace{\left(t-E^{\prime}\left(q_{h}^{*}\right)\right)}_{(-)}(\underbrace{p^{\prime \prime}\left(Q^{*}\right)}_{(-)} \underbrace{\frac{d q_{f}^{*}}{d c}}_{(+)}+\underbrace{\left(p^{\prime \prime \prime}\left(Q^{*}\right) q_{f}^{*}+p^{\prime \prime}\left(Q^{*}\right)\right)}_{(*)} \underbrace{\frac{d Q^{*}}{d c}}_{(-)}) .
\end{aligned}
$$

Both increase with a decrease in $c$ when the inverse demand function is linear because the second term in $d G / d c$ is zero $\left(p^{\prime \prime}=p^{\prime \prime \prime}=0\right)$. Under the linear demand assumption, when $E^{\prime \prime}$ is large enough ( $\gamma$ in $E D$ is large enough), the absolute value of $d G / d c$ is larger than that of $d\left(\left(p^{\prime}\right)^{2} Q^{*}\right) / d c$. That is, a decrease in $c$ enhances the equilibrium tax level, $t$. Even though the inverse demand is not linear, if the absolute value in the large parentheses is small, the absolute value of $d G / d c$ is more likely larger than that of $d\left(\left(p^{\prime}\right)^{2} Q^{*}\right) / d c$. 